\title{
APOSENTADORIA ESPECIAL E REFORMA DA EMENDA CONSTITUCIONAL No 103/2019: ANÁLISE DA CONSTITUCIONALIDADE EM FACE DO PRINCÍPIO DA VEDAÇÃO AO RETROCESSO SOCIAL
}

\author{
Elísio Nascimento Batista Júnior ${ }^{1}$ \\ Carlos Rafael da Silva ${ }^{2}$
}

\section{RESUMO}

O presente artigo tem por objetivo analisar a questão da constitucionalidade da alteração processada na aposentadoria especial pela reforma previdenciária da Emenda Constitucional $\mathrm{n}^{\mathrm{o}} 103 / 2019$, especificamente no ponto que introduz a idade como um dos fatores para a concessão do benefício. $\mathrm{O}$ estudo é realizado com fundamento no princípio da vedação ao retrocesso social, tangenciando os argumentos da reserva do possível e do mínimo existencial. A pesquisa é de natureza teórico-bibliográfica e documental, seguindo o método descritivoanalítico que instruiu a análise da legislação constitucional, infraconstitucional e jurisprudencial, bem como doutrinária.

Palavras Chaves: Aposentadoria Especial; Reforma; Vedação ao Retrocesso.

\section{SPECIAL RETIREMENT AND REFORM OF CONSTITUCIONAL AMENDMENT No 103/2019: ANALYSIS OF CONSTITUTIONALITY IN FACE OF PRINCIPLE OF PROHIBITION AGAINST SOCIAL RETROGRESSION}

\begin{abstract}
This article analyze the question of the constitutionality of the alteration processed in special retirement by the social security reform carried out by Constitutional Amendment $\mathrm{n}^{\mathrm{o}}$ $103 / 2019$, specifically in the point that introduces the age as a requirement for the granting of the benefit. The study is carried out based on the principle of the prohibition against social retrogression, following the arguments of the reserve of the possible and the existential minimum. It is a theoretical-bibliographical-natured research guided by a descriptiveanalytical method which had instructed the analysis of constitutional and infraconstitutional laws, as well as the doctrine.
\end{abstract}

Keywords: Special Retirement; Reform; Backward Sealing.

\section{INTRODUÇÃO}

O desenvolvimento dos direitos fundamentais não ocorre de forma linear na nossa história, mas em um contínuo processo de avanços e retrocessos constante, com prevalência

\footnotetext{
${ }^{1}$ Juiz Federal. Professor da Universidade de Itaúna: Direito Administrativo. Mestrando em Proteção dos Direitos Fundamentais da Universidade de Itaúna/MG. Especialista em Direito Processual Público Universidade Federal Fluminense. Graduado em Direito Universidade Federal de Minas Gerais. E-mail: elisionbjunior@ gmail.com.

2 Mestrando em Proteção dos Direitos Fundamentais da Universidade de Itaúna. Advogado. E-mail: crafaelsilva28@gmail.com.
} 
para o primeiro, o que pressupõe um crescente desenvolvimento do sistema de direitos e garantias fundamentais. Esse processo se aplica a todas as gerações de direitos fundamentais, portanto se estende aos direitos sociais que por sua característica positiva, que demandam uma atuação do Estado para sua implementação, por consequência sofrem de forma mais presente esse processo claudicante de concretização.

Esses retrocessos da proteção social ocorrem por diversas razões, porém de forma preponderante em face de questões econômicas, que reduzem a capacidade de investimento financeiro do Estado. Assim, na disputa política pelas benesses do poder público, as categorias menos organizadas e poderosas tendem a perder suas proteções e direitos.

Dentro dessa realidade uma das áreas mais atacadas é a social, na vertente assistência e previdência, que veem reduzidas as redes de proteção dos cidadãos que dependem dessas políticas públicas para manter sua dignidade enquanto pessoa humana.

Seguindo este Norte, o artigo tem por objeto o estudo da constitucionalidade da reforma do regime geral de previdência social, notadamente no que tange à introdução do requisito da idade para a concessão da aposentadoria especial, tendo por base o princípio da vedação ao retrocesso social.

No primeiro tópico, após a introdução, analisa-se, em um primeiro momento, o desenvolvimento dos direitos fundamentais, em especial dos direitos sociais, que se caracteriza por uma linha com constantes avanços e retrocessos. Em face desta realidade, aborda-se, em seguida, o princípio da vedação ao retrocesso, com base na doutrina do Professor JJ Gomes Canotilho e nas decisões do Tribunais Constitucionais Alemão e Português. A aplicação deste princípio é estudada em comparação com o argumento da reserva do possível e o princípio do mínimo existencial.

Em seguida, o segundo tópico estuda a criação e desenvolvimento do benefício previdenciário da aposentadoria especial. A pesquisa tem por foco a questão dos requisitos exigidos para a concessão do benefício, desde sua criação até a legislação vigente antes da reforma constitucional, verificando, em especial, a questão da idade mínima como requisito para acessar a parcela. Analisando a razão das alterações legislativa, busca-se encontrar os fundamentos que embasaram evolução legislativa, se essas alterações tendem a uma proteção social mais efetiva ou acarretaram a redução desse seguro do trabalhador.

$\mathrm{Na}$ conclusão avalia-se, com base nos fundamentos e análises explanadas no texto a questão da constitucionalidade da alteração processada pela referida emenda constitucional 
que introduziu como requisito para a concessão da aposentadoria especial uma idade mínima ou um sistema de pontuação que tem como um dos parâmetros de cálculo a idade.

Este artigo tem como marco teórico o estudo de Canotilho sobre a aplicação do princípio da vedação ao retrocesso social, com base nas decisões proferidas pelos Tribunais Constitucionais Alemão e Português.

\section{DIREITOS SOCIAIS: PRINCÍPIO DA VEDAÇÃO AO RETROCESSO}

A busca pela consolidação dos direitos fundamentais, com especial atenção para os direitos de cunho prestacional, que demandam aporte financeiro por parte do Estado, é uma constante na humanidade. O desenvolvimento social não é homogêneo, pois a proteção social está sujeita a fatores conhecidos como pressupostos de direitos fundamentais que são diversos entre os países e regiões do planeta, o que acarreta o conhecido desnível que observamos. Tampouco é um avanço linear rumo a uma proteção ideal, sendo um caminho marcado por constantes progressos e retrocessos. Traço comum é a luta diária pela implementação dos direitos fundamentais e a manutenção das conquistas alcançadas.

Essa realidade é vivenciada da mesma forma em nosso país, sendo as conquistas sociais constantemente ameaçadas por questões de cunho econômico ou ideológico. Com a atual crise financeira do Estado brasileiro, iniciada com a crise econômica do subprime e potencializada pela atual pandemia da COVID-19, os gestores vêm buscando diversas formas de reduzir os déficits orçamentários. Nesse embate político, os direitos sociais são uma das primeiras vítimas da tentativa do Estado de reduzir seus custos. A reforma previdenciária realizada através da Emenda Constitucional n. 103/2019 atacou diversas distorções na previdência social, todavia promoveu alterações que culminaram na redução, quando não extinção, de diversos direitos previdenciários do trabalhador brasileiro.

Importante ressaltar que essa luta pela manutenção dos avanços sociais não é questão recente, mas permanente desde a existência da humanidade e a compreensão dos direitos humanos como um direito natural de todo homem. Nesse embate político sempre se apresentam forças que buscam subjugar seus semelhantes na busca de uma maior posição de poder ou riqueza, como recorda HORTA (1995, p. 263).

A conquista e a defesa dos direitos individuais é uma tarefa diária, um esforço de todas as horas. Esta luta incessante é benéfica às liberdades e à conservação, pois, como no belo conceito do pensador francês, que Milton Campos estimava recordar: 
se impedíssemos cada dia que se levasse uma pedra para a Bastilha, nós nos pouparíamos o trabalho de demoli-la.

Esses direitos fundamentais, que devem ser diariamente protegidos, são de acordo com FERRAJOLI (2011), as normas que protegem os mais fracos contra o poder e as leis dos mais forte. Pode-se dizer que são as normas que defendem os mais fracos da sociedade, possibilitando a atuação dos demais atores políticos, primordialmente o Poder Judiciário, no seu exercício contramajoritário.

Esses direitos, historicamente, são considerados aqueles direitos naturais do ser humano que se encontram positivados em determinada ordem jurídica por meio de normas de natureza constitucional. Nas palavras de CANOTILHO (2001, p. 375), citando Cruz Villalon: Onde não há Constituição não haverá direitos fundamentais. Apesar de conceituados pela doutrina como direitos naturais, na realidade, os direitos fundamentais são uma construção da humanidade que no curso de sua existência incorpora como naturais construções sociais, filosóficas e religiosas.

\footnotetext{
Ora, foi a secularização do direito natural pela teoria dos valores objetivos da escolástica espanhola (Francisco de Vitória, Vazques e Suarez) que, substituindo a vontade divina pela natureza ou razão das coisas, deu origem a uma concepção secular de direito natural, posteriormente desenvolvida por Grotius, Pufendorf e Locke. (CANOTILHO, 2001, p. 380)

...

Os direitos do homem não se baseiam apenas em grandezas invariáveis jusnaturalisticamente formuladas. Deduz-se isso das considerações feitas em 5. e 6. Nas quais é patente sua conexão com as constelações histórico-sociais. Neste momento apenas se acentuará a ideia da interdependência da instância filosófico jurídica dos direitos fundamentais com a instância econômica. (CANOTILHO, 2001, p. 383)
}

A necessidade do capitalismo de uma segurança nas relações comerciais forja as bases para fixação de um estatuto social estável, no qual se vejam reconhecidos os direitos liberais, sendo os direitos do cidadão burguês protegido e estendido a toda a humanidade. Forma-se assim a ideia de garantir a toda humanidade um rol de direitos que lhe possibilite uma existência no plano social, econômico, cultural e religioso, firmando-se um arcabouço de regras fundamentais para o desenvolvimento da pessoa humana. O sistema em ascensão não mais admitia relações sociais que se alteravam com base no humor do monarca, fato que demandou uma maior garantia para toda a humanidade.

Assim, podemos traçar uma linha de desenvolvimento dos direitos fundamentais, passando pela Bill of Rights (1776) e a Declaração dos Direitos do Homem e do Cidadão da Revolução Francesa (1789), culminando com o período da constitucionalização desses 
direitos, quando passaram a possuir no âmbito interno de cada país a caracterização de direitos fundamentais da pessoa humana.

A implementação dos direitos fundamentais, especialmente os direitos sociais, de natureza prestacional, passa pela atuação do Estado com a definição de seu papel de instância provedora/protetora dessa garantia do cidadão. A doutrina classifica os direitos fundamentais em direitos de defesa (negativos) e direitos prestacionais, referida divisão tem como origem a teoria dos status de JELLINEK, que desenvolveu a tese dos quatros status dos direitos fundamentais (status libertatis, status subjectiones, status civitatis e status activus civitatis).

Neste sentido, desenvolveu-se a doutrina, com a existência de direitos de prestação e direitos de defesa (negativos). Sendo os últimos aqueles que protegem o cidadão ao limitar a atuação do Estado. Também chamados de direitos de primeira dimensão, foram os primeiros direitos reconhecidos, posto que ligados ao liberalismo econômico, tendo como fundamento a liberdade de atuação do cidadão, que pressupõe a vedação da interferência do Estado. Como exemplo podemos citar o direito à vida, integridade física, liberdade de expressão, propriedade privada etc.

Em contrapartida, os direitos de prestação pressupõem uma atuação positiva por parte do Estado, pois concede a pessoa humana o direito de exigir o cumprimento de determinada obrigação (prestação). Nas palavras de ALEXY (2002, p. 427) corresponde a contraposição exata do direito de defesa. Estes direitos estão ligados à proteção do cidadão com amplo espectro de atuação, desde a proteção deste frente a outro cidadão (por meio do direito penal) até prestações em dinheiro e bens.

A eficácia pressupõe, como explica ALEXY (2002), que tratem-se de direitos subjetivos de caráter normativo-constitucional, devendo os mesmos estarem previsto nas normas constitucionais.

\footnotetext{
Os direitos do tipo indicado são direitos fundamentais à prestações apenas se tratar de direitos subjetivos e constitucionais. Em tanto tais, tem que ser diferenciados, por uma parte, dos direitos subjetivos e não constitucionais, e de outra, das normas que não conferem direitos subjetivos (ALEXEY, 2002, p. 427)
}

Assim, em muitos casos, para a efetiva implementação, o Estado demanda a realização de políticas públicas que pressupõe a alocação de recursos de acordo com os interesses públicos e necessidades do cidadão. Portanto, a efetividade está vinculada a um conjunto de condições econômicas, sociais e culturais que a doutrina designa como pressupostos de direitos fundamentais. 
Consideram-se pressupostos de direitos fundamentais a multiplicidade de factores capacidade econômica do Estado, clima espiritual da sociedade, estilo de vida, distribuição de bens, nível de ensino, desenvolvimento econômico, criatividade cultural, convenções sociais, ética filosófica ou religiosa - que condicionam, de forma positiva ou negativa a existência e proteção dos direitos econômicos, sociais e culturais. (CANOTILHO, 2001, p. 469)

Concretizada determinada parcela desses direitos prestacionais, passa a assistir a todo cidadão o acesso igualitário a essa determinada prestação, na medida da sua necessidade. Esse acesso igualitário é denominado pela doutrina como direito derivado a prestação (CANOTILHO, 2001, p. 475), sendo traduzido na quota parte isonômica que todo e qualquer cidadão deve ter acesso as prestações públicas. É dever do Estado e desta forma ele se legitima quando trata todos os cidadãos com igual respeito e igual consideração (DWORKIN, 2002, p. 9 e 10). Essa aplicação do princípio da igualdade deve orientar a atuação do Estado enquanto fornecedor de políticas públicas, cabendo-lhe, em um processo constante de dialogo democrático, proceder a distribuição de todas as políticas públicas para atender primordialmente os mais necessitados, subindo aos poucos para os patamares mais elevados da sociedade.

Quando o Estado brasileiro aderiu ao Pacto de San Jose da Costa Rica, comprometeu-se a progressivamente implementar os direitos socais (art. 26), por consequência, internalizou, positivando, o princípio da vedação ao retrocesso, pois cabe ao Estado a obrigação manter a progressividade crescente dos direitos já concretizados. Portanto, sob pena de atentar contra a norma fundamental prevista no tratado, está impedido de reduzir os direitos já concretizados em normas infraconstitucionais.

A evolução dos direitos fundamentais e sua concretização devem sempre observar um crescimento positivo, de forma que se busque alcançar uma sociedade igualitária, ou ao menos com a redução significativa das desigualdades sociais inerentes ao sistema capitalista. Esse pressuposto caminha ao lado dos objetivos fundamentais de nossa república que é a construção de uma sociedade livre, justa e solidária, erradicando a pobreza e a marginalização, buscando reduzir as desigualdades, nos termos do artigo $3^{\circ}$. Em conclusão, a vedação ao retrocesso é um princípio que representa a máxima do Estado Democrático e Social de Direito, nas palavras de BARROSO (2001, p. 158)

O princípio da proibição do retrocesso decorre justamente do princípio do Estado Democrático e Social de Direito, do princípio da dignidade da pessoa humana, do princípio da máxima eficácia e efetividade das normas definidoras dos direitos 
fundamentais, do princípio da proteção da confiança e da própria noção do mínimo existencial.

Apesar desta sólida construção em torno do princípio da vedação ao retrocesso, o fato é que não há no ordenamento jurídico uma norma que se aplique de forma absoluta. Em determinadas circunstâncias um princípio deve ceder lugar a outro, que irá preponderar no caso concreto (BONAVIDES, 2003, p. 280).

Com a implementação do Estado do Bem-Estar Social, a partir da segunda grande guerra, houve um crescimento significativo dessa proteção social, com a implementação de diversos direitos sociais que antes não eram atendidos pelo Poder Público. O Estado passou a ter uma fundação redistributiva dos bens da sociedade, de forma a melhorar a qualidade de vida dos hipossuficientes (VIDAL, 2017, p. 219).

Ocorre que a partir da década de 70 diversos Estados se viram inviabilizados financeira de manter todos os direitos sociais anteriormente concedidos e iniciaram um processo de desestruturação e desmonte dessa proteção. Esse movimento de extinção dos direitos sociais é que acarretou no desenvolvimento do princípio da vedação ao retrocesso.

Essencial observar que o princípio da vedação ao retrocesso, não importa em total imutabilidade da proteção social, mas na vedação da sua exclusão. Significa que não há vedação na substituição de uma política de proteção social por outro direito, bem como pode ocorrer a sua redução (VIDAL, 2017, p. 223). A vedação está voltada para a total exclusão do direito social, posto que se garante um mínimo de proteção ao hipossuficiente, não sendo possível a exclusão da referida proteção do ordenamento jurídico. Assim, esse direito deve ser interpretado conjuntamente com o princípio do mínimo existencial, a manutenção de uma cota mínima para preservar a dignidade da pessoa humana.

Todavia, a efetividade desse princípio não pode levar a uma completa desestruturação financeira do Estado, sob pena de agravar a situação das pessoas que mais necessitam do amparo. Alterações, quando necessárias, devem ser feitas, porém de forma justa e proporcional para toda a sociedade. Ressalte-se que essas alterações devem se apresentar apenas quando extremamente necessárias, sendo uma exceção na régua do desenvolvimento dos direitos sociais.

A questão que se apresenta é como compatibilizar esse princípio com o argumento da reserva do possível. De acordo com Holmes e Sustein (2015, p. 69), todo direito tem um custo, mesmo os direitos negativos, geram algum custo para o Estado, ainda que ínfimo, pois 
mesmos esses têm caráter positivo. Esse baixo custo não se repete no âmbito dos direitos de natureza prestacional que demanda vultuosos gastos por parte do Estado para implementá-los. A depender do volume de gastos a concessão deste direito pode acarretar uma completa falência do Estado, causando maior prejuízos que benefícios.

Neste ponto, há que se considerar a questão da reserva do possível, pois dentre os pressupostos de direitos fundamentais, citados por CANOTILHO (2001), inclui-se a questão econômica. Porém, deve-se ter o cuidado ao utilizar o argumento da reserva do possível, pois a questão orçamentária não pode ser fundamento para total restrição de direitos sociais. Assim fica o questionamento, como compatibilizar a capacidade financeira do Estado com a vedação ao retrocesso social.

CANOTILHO (2001) entende por uma aplicação mais rigorosa da vedação ao retrocesso, o direito social implementado é uma garantia institucional do cidadão, guarda de flanco, que não pode ser alterada pelo Estado sem a devida compensação ou alternativa. Neste ponto, reforça seu entendimento com base na decisão do Tribunal Constitucional Português, no Acórdão TC no 39/84, que declarou inconstitucional a norma infraconstitucional que praticamente extinguia o Serviço Nacional de Saúde.

A doutrina aqui defendida mereceu aplauso jurisprudencial no Acórdão do TC $\mathrm{n}^{\circ}$
$39 / 84(D R, I, 5-5-1984)$ que declarou inconstitucional o DL $\mathrm{n}^{\circ} 254 / 82$ que revogara
grande parte da L. ${ }^{\circ} 56 / 79$, de $15 / 79$, criadora do Sistema Nacional de Saúde. Nessa
importante decisão escreveu-se de forma incisiva e paradigmática: 'a partir do
momento em que o Estado cumpre (total ou parcialmente) as tarefas
constitucionalmente impostas para realizar um direito social, o respeito
constitucional deste deixa de consistir (ou deixa de consistir apenas) numa obrigação
positiva, para se transformar ou passar também a ser uma obrigação negativa.
(CANOTILHO, 475)

No direito alemão, a aplicação do princípio na jurisprudência iniciou do entendimento de que se a propriedade privada é garantida como um direito do cidadão para seu sustento, não podendo ser reduzida, o mesmo raciocínio se aplica a previdência (COSTA, 2013, p. 60). A doutrina alemã defende a aplicação deste princípio como uma proteção ao mínimo existencial, núcleo essencial dos direitos fundamentais, podendo haver redução desde que não gere restrições arbitrárias que atentem contra o conteúdo essencial do direito a uma existência digna (COSTA, 2013, p. 63).

Posteriormente, a doutrina alemão passou a ter maior influência no pensamento constitucional português, estabelecendo-se um debate acerca da observância, pelo legislador das imposições legislativas constitucionais. Surge, portanto, a questão da proteção ao núcleo essencial dos direitos fundamentais, primeiramente, sob o âmbito 
da limitação da reversibilidade dos direitos adquiridos e das expectativas de direito e, posteriormente, defendendo a liberação de atuação e legitimidade do legislador para estabelecer os parâmetros infraconstitucionais dos direitos sociais, a partir de decisões políticas, desde que tais decisões não gerem restrições arbitrárias que atinjam o conteúdo essencial do direito à existência mínima garantida pela dignidade da pessoa humana.

Assim, de acordo com o entendimento doutrinário, a aplicação do princípio da vedação ao retrocesso não é absoluta, podendo dialogar com a questão da reserva do possível, devendo sempre observar que eventuais restrições não podem ser arbitrárias, nem atingir o núcleo essencial do mínimo existencial, sob pena de fulminar o princípio da dignidade da pessoa humana.

Cabe verificar, desta forma, a amplitude da aplicação do conceito do mínimo existencial, posto que é um dos instrumentos que irá balizar a análise de eventual retrocesso de um direito social. Cediço que sua definição é controversa e depende do nível de desenvolvimento socioeconômico de cada Estado. Apesar de a doutrina tentar estabelecer a existência de um mínimo como um conjunto de condições elementares ao homem, como forma de assegurar sua dignidade, sem que a faixa limítrofe do estado pessoal da subsistência seja desrespeitada (LAZARI, 2016, p. 70), o que se verifica é que a concretização deste mínimo vai depender da possibilidade de cada Estado, resguardando-se um piso na subsistência.

Nesta linha, a implementação dos direitos fundamentais passa por questões como o custo para a implementação, podendo a escassez de recursos pode obstar a satisfação dos cidadãos.

A efetivação dos direitos fundamentais deve ter por piso a existência do direito ao mínimo existencial, aquela parcela que não está sob o julgo do Estado e lhe impõe a atuação para garantir condições mínimas de existência humana digna. Questão que segue aberta é a dimensão do que vem a ser mínimo existencial como garantia para a dignidade da pessoa humana. Seria apenas a parcela destinada à sobrevivência do cidadão do ponto de vista fisiológico (alimentação, saúde e moradia) ou incluiria outras parcelas destinadas a garantir uma existência digna na sociedade, como direitos sociais necessários, tais como segurança, cultura, lazer, transporte, trabalho e inatividade. Não há uma definição predominante sobre o tema, sendo a questão tratada de forma pontual e sem positivação, conforme afirma TORRES (1989). 
Carece o mínimo existencial de conteúdo específico. Abrange qualquer direito, ainda que originariamente não-fundamental (direito à saúde, à alimentação etc.), considerado em sua dimensão essencial e inalienável. Não é mensurável, por envolver mais os aspectos de qualidade que de quantidade, o que toma difícil estremá-lo, em sua região periférica, do máximo de utilidade (maximum welfare, Nutzenmaximierung), que é princípio ligado à ideia de justiça e de redistribuição da riqueza social. Certamente esse mínimo existencial, se o quisermos determinar precisamente, é uma incógnita muito variável.

O problema do mínimo existencial confunde-se com a própria questão da pobreza. Aqui também há que se distinguir entre a pobreza absoluta, que deve ser obrigatoriamente combatida pelo Estado, e a pobreza relativa, ligada a causas de produção econômica ou de redistribuição de bens, que será minorada de acordo com as possibilidades sociais e orçamentárias. De assinalar, todavia, que inexiste definição apriorística de pobreza absoluta, por ser variável no tempo e no espaço e, não raro, paradoxal, surgindo tanto nos países ricos como nos pobres.

Desta forma, a questão passa pela condição social de cada país em verificar dentro das condições fáticas de sua sociedade qual o grau de mínimo existencial deve ser implementado, sem olvidar o princípio da dignidade da pessoa humana. Portando a fixação deste piso não pode ser rasteiro a ponto de impedir que a pessoa tenha uma vida digna, ainda que seja o gozo da inatividade de forma digna.

\section{APOSENTADORIA ESPECIAL: EVOLUÇÃO}

Estabelecida a questão a aplicação do princípio da vedação ao retrocesso, cabe verificar a evolução do benefício da aposentadoria especial. Trata-se de parcela previdenciária que tem por norte proteger o trabalhador de eventuais prejuízos danosos a sua saúde e integridade física, em razão do exercício de seu trabalho em contato com agentes nocivos ou perigosos. Este benefício encontra-se previsto em âmbito constitucional no artigo 201, $\S 1^{\circ}$, sendo regulado nos artigos 57 e 58 da lei no 8.213 de 1991.

Incluída no gênero das aposentadorias que engloba ainda a aposentadoria por idade e invalidez, a aposentadoria especial tem por objetivo a proteção à saúde e integridade física do trabalhador. Neste ponto, a doutrina entende que este benefício tem como natureza jurídica ser, nas palavras de Wladimir Novais Martinez (2001, p. 21), uma indenização social pela exposição aos agentes nocivos ou possibilidade de prejuízo à saúde do trabalhador. No mesmo sentido, entende Maria Helena Carreira Alvim Ribeiro (2004, p. 24), que conceitua o benefício como sendo uma compensação pelos desgastes resultante do tempo de serviço prestado em condições prejudiciais à saúde e integridade física. 
No regime de previdência nacional, o benefício surgiu com a LOPS - Lei Orgânica da Previdência Social - Lei no 3.897 de 1960, que estabelecia o direito à aposentadoria aos segurados que exercessem atividade consideradas nocivas por um período de 15, 20 ou 25 anos, desde que tivessem, no mínimo, 50 anos de idade. Na origem, o benefício tinha como pressuposto, além do trabalho com risco à saúde e integridade física, também o requisito idade, fato que acarretava o exercício da atividade por um período superior ao limite estabelecido pela ciência médica.

Os prazos de 15, 20 ou 25 anos, são estabelecidos tendo em vista estudos que definem um tempo limite em que o corpo humano suporta, com menores riscos, o contato com os agentes agressores descritos na legislação e regulamentos. Desta forma, após o tempo estabelecido a permanência do contato com o agente agressor, deixa de ser uma hipótese de risco à saúde para se tornar uma certeza de prejuízo à saúde do trabalhador. Em pesquisa realizada no grupo de mineradores, uma das atividades consideradas mais insalubre, chegouse à seguinte conclusão (VERISSIMO, 2013):

Há muito tempo a mineração e seus processos são reconhecidamente ocupações perigosas e suscetíveis a diversas doenças. Os riscos estão associados às condições, muitas vezes insalubres, do ambiente de trabalho, já que a atividade mineradora, a céu aberto ou não, libera poeiras contendo resíduos minerais. Além dos perigos por fumos e gases nocivos, têm-se exposição à radioatividade, baixa concentração de oxigênio, temperatura elevada e estresse.

Nossos resultados sugerem que os mineradores brasileiros tiveram um aumento no risco de morte por todas as neoplasias e especificamente para câncer de traqueia/brônquio/pulmão, ao longo dos períodos estudados, quando comparados com a população geral. Resultados semelhantes têm sido observados em estudos sobre a mortalidade de mineradores publicados em todo o mundo, na tentativa de investigar uma associação entre essa ocupação e doenças neoplásicas

As consequências a longo prazo do contato com os agentes nocivos são devastadoras para a saúde dos trabalhadores, razão pela qual em uma reforma do sistema previdenciário ocorrida em 1973, pela Lei $n^{\circ} 5.890$, a concessão do benefício de aposentadoria especial deixou de ter como condição uma idade mínima, possibilitando assim que o trabalhar passe para a inatividade depois do tempo máximo admitido pela área médica. Desta forma, buscouse preservar a dignidade e saúde da pessoa do trabalhador, evitando maiores prejuízos em razão da atividade exercida.

Percebe-se que a evolução da proteção a este direito social ocorreu poucos anos após a concretização do benefício, mais especificamente, após 13 anos de sua criação. Este fato chama a atenção para a importância de se limitar o tempo de atividade em contato com os 
agentes nocivos, pois do contrário estará se impondo ao trabalhador uma certeza no desenvolvimento de uma doença profissional que irá lhe afetar pelo resto da vida, em total afronta ao princípio da dignidade da pessoa humana. $\mathrm{O}$ risco do desenvolvimento de uma doença profissional passa a se tornar uma certeza quando o tempo previsto é extrapolado.

A proteção ao benefício sem o requisito idade perdurou até a reforma constitucional do regime geral da previdência social, perpetrada pela Emenda Constitucional $\mathrm{n}^{\circ} 103$ de 2.019, que novamente retrocedeu na concessão do benefício. Nos termos da Emenda, a concessão do benefício regrediu 50 anos, voltando a ter como requisito uma idade mínima para o trabalhador ou, no caso dos que já se encontravam vinculado ao regime geral, um sistema de pontos que leva em consideração a idade do trabalhador ${ }^{3}$. Na realidade podemos dizer que houve um agravamento da situação, pois na origem exigia-se uma idade mínima de 50 anos, sendo que a nova configuração exige idade superior.

${ }^{3}$ Art. 201.

$\S 1^{\circ}$ É vedada a adoção de requisitos ou critérios diferenciados para concessão de benefícios, ressalvada, nos termos de lei complementar, a possibilidade de previsão de idade e tempo de contribuição distintos da regra geral para concessão de aposentadoria exclusivamente em favor dos segurados:

II - cujas atividades sejam exercidas com efetiva exposição a agentes químicos, físicos e biológicos prejudiciais à saúde, ou associação desses agentes, vedada a caracterização por categoria profissional ou ocupação.

Art. 19.

$\S 1^{\circ}$ Até que lei complementar disponha sobre a redução de idade mínima ou tempo de contribuição prevista nos $\S \S 1^{\circ}$ e $8^{\circ}$ do art. 201 da Constituição Federal, será concedida aposentadoria:

I - aos segurados que comprovem o exercício de atividades com efetiva exposição a agentes químicos, físicos e biológicos prejudiciais à saúde, ou associação desses agentes, vedada a caracterização por categoria profissional ou ocupação, durante, no mínimo, 15 (quinze), 20 (vinte) ou 25 (vinte e cinco) anos, nos termos do disposto nos arts. 57 e 58 da Lei $n^{\circ} 8.213$, de 24 de julho de 1991, quando cumpridos:

a) 55 (cinquenta e cinco) anos de idade, quando se tratar de atividade especial de 15 (quinze) anos de contribuição;

b) 58 (cinquenta e oito) anos de idade, quando se tratar de atividade especial de 20 (vinte) anos de contribuição; ou

c) 60 (sessenta) anos de idade, quando se tratar de atividade especial de 25 (vinte e cinco) anos de contribuição;

Art. 21. O segurado ou o servidor público federal que se tenha filiado ao Regime Geral de Previdência Social ou ingressado no serviço público em cargo efetivo até a data de entrada em vigor desta Emenda Constitucional cujas atividades tenham sido exercidas com efetiva exposição a agentes químicos, físicos e biológicos prejudiciais à saúde, ou associação desses agentes, vedada a caracterização por categoria profissional ou ocupação, desde que cumpridos, no caso do servidor, o tempo mínimo de 20 (vinte) anos de efetivo exercício no serviço público e de 5 (cinco) anos no cargo efetivo em que for concedida a aposentadoria, na forma dos arts. 57 e 58 da Lei ${ }^{\circ} 8.213$, de 24 de julho de 1991, poderão aposentar-se quando o total da soma resultante da sua idade e do tempo de contribuição e o tempo de efetiva exposição forem, respectivamente, de:

I - 66 (sessenta e seis) pontos e 15 (quinze) anos de efetiva exposição;

II - 76 (setenta e seis) pontos e 20 (vinte) anos de efetiva exposição; e

III - 86 (oitenta e seis) pontos e 25 (vinte e cinco) anos de efetiva exposição. 
O novo sistema adotado obriga que o trabalhador, para gozar do benefício de aposentadoria especial, permaneça em atividade até a idade de 55, 58 e 60, para atividades nocivas à saúde com tempo de contribuição, respectivamente, de 15, 20 e 25 anos.

O sistema, na forma adotada obrigará que o trabalhador permaneça efetivamente tempo muito superior ao patamar de tempo de contribuição especificado na lei. Na grande maioria das hipóteses de atividades nocivas à saúde, os trabalhadores são pessoas com baixa ou média instrução, sem acesso ao ensino superior. Assim, iniciam na vida profissional com a idade entre dezoito e vinte um anos, pois os trabalhos exigem força física própria da juventude.

Desta forma, esse trabalhador, caso inicie sua atividade com 21 anos, completará o tempo de atividade muito antes de completar a idade mínima, obrigando-o a permanecer praticamente $60 \%$ (sessenta por cento) a mais na atividade prejudicial à saúde.

O mesmo raciocínio se aplica aos segurados que já se encontram vinculado ao regime de previdência pois deverão completar no somatório da idade, mais tempo de contribuição e tempo de efetiva exposição o resultado de 66,76 ou 86 , respectivamente para as efetivas exposições exigidas de, respectivamente, 15, 20 ou 25 anos, conforme estabelece o artigo 21 da Emenda Constitucional no 103/2019.

Percebe-se claramente que o objetivo da alteração foi aumentar o tempo de atividade do trabalhador, tendo o governo utilizado o subterfúgio de estabelecer uma idade mínima ou vincular a concessão ao somatório da idade, tempo de efetiva exposição e tempo de contribuição. A alternativa utilizada tem por objetivo claro não discutir a questão de aumentar o tempo de atividade em contato com agentes nocivos, pois o governo teria de debater com o congresso sobre as sequelas do contato em tempo superior, que serão mais graves para a saúde do trabalhador, podendo em muitos casos vir a óbito antes mesmo de completar a idade para a aposentadoria.

Assim, utilizando a fixação de uma idade mínima, o Estado se esquivou de debater este ponto crucial da aposentadoria especial, mas ciente de que os trabalhadores permanecerão em atividade por tempo superior. $\mathrm{O}$ trabalhador já estará treinado e com larga experiência na atividade, sendo improvável - senão impossível - mudar de ramo para exercer outra atividade sem contato com agente nocivo.

Desta forma, a alteração processada acabará por manter o trabalhador por período aproximado de 30 anos em atividades nocivas à saúde e integridade física. 


\section{CONCLUSÃO}

O estudo do tema demonstrou que não há no direito a aplicação de um princípio de forma absoluta, devendo este ser compatibilizado com o próprio ordenamento jurídico e os demais princípios nele vigentes. $\mathrm{O}$ estudo sobre a compatibilização de princípios passa pelos ensinamentos de ALEXY (2002) que estabeleceu os parâmetros de otimização, proporcionalidade e razoabilidade, como requisitos para se sopesar a aplicação no caso concreto.

Desta forma, na ponderação de valores/princípio, deve-se buscar uma aplicação sempre com bom senso, dentro de padrões de aceitabilidade social, observando a forma que seja a mais adequada, necessária e que os benefícios superem os eventuais prejuízos gerados. Os direitos fundamentais não fogem dessa máxima, cabendo aos operadores busca uma interpretação que melhor se adeque aos padrões de razoabilidade e proporcionalidade.

Assim, a aplicação do princípio da vedação ao retrocesso não pode ser absoluta, de forma a impedir que o Estado, uma vez implementado um direito social, se veja engessado na sua manutenção. Alterações são necessárias, seja para tornar mais eficiente a proteção social, seja para adequar referido direito a novas condições econômicas da sociedade.

A proteção, conforme se verifica nas decisões dos Tribunais Constitucionais da Alemanha e Portugal, é proibir que haja uma total extinção de uma proteção social sem sua substituição por outra medida protetiva ou uma redução drástica sem justificativa plausível (reduções arbitrárias). Ademais, deve ser observado pelo Estado a proteção ao mínimo existencial, ou seja, aquela parcela mínima de proteção que garanta a dignidade da pessoa humana.

Analisando a alteração processada na Aposentadoria Especial pela Emenda Constitucional $n^{\circ} 103 / 2019$, percebe-se claramente que não houve esse cuidado por parte do constituinte derivado.

A aposentadoria especial se caracteriza por uma forma de inatividade do trabalhador que exerce seu labor sujeitos a condições que após determinando período de contato pode lhe acarretar graves danos à saúde. Desta forma, o legislador, com base em estudos médicos, estabeleceu determinadas atividades que após um período de 15, 20 ou 25 anos, possibilitam o acesso a inatividade remunerada. 
A introdução do requisito idade para a concessão do benefício subverte o entendimento de que o tempo de contato com a agente nocivo é que determina a necessidade da inatividade, pois além deste, deverá o trabalhador possuir a idade mínima de 55, 58 ou 60 anos ou completar em um sistema de pontos o somatório de 66, 76 ou 86 pontos.

A alteração foi realizada sem qualquer estudo científico/médico que demonstram a inexistência de prejuízo para a saúde do trabalhado. A única razão foi a tentativa de aumentar a idade média das aposentadorias e reduzir o gasto da previdência, sem se preocupar com a questão própria deste benefício. Desta forma, a alteração se torna drástica, pois não possui uma justificativa plausível, que não seja a mera questão das aposentadorias precoces.

Na questão econômica, é importante alertar que diversas categorias mantiveram seus privilégios com concessão de benefícios em idade inferior ao da aposentadoria especial, como é o caso dos militares e profissionais da área de segurança pública. Portanto, este ponto, por si, não é justificativa plausível para o agravamento dos requisitos. Se havia possibilidade de manter o benefício de aposentadoria com idade reduzida para atividades perigosas, não se mantem o argumento de reformá-lo para as atividades nocivas à saúde e integridade física. Neste ponto, importante recordar os ensinamentos de DWORKIN (2011), que o Estado se legitima quando trata todos com o mesmo respeito e consideração. Adotar posicionamentos diversos para situações equivalente, torna odioso o benefício concedido aos servidores da área de segurança ou iníqua a alteração processada na aposentadoria especial.

A norma constitucional fere, de igual forma, o princípio do mínimo existencial, forçando o trabalhador a ampliar seu tempo de atividade, praticamente dobrando-o, fato que pode levar a total ruína da saúde do indivíduo, caso permaneça todo esse tempo na atividade em contato com agentes nocivos. Apesar de não haver obrigatoriedade de que todo esse período seja exercido na atividade especial, é de se esperar que um trabalhador que já encontra-se empregado e treinado para determinada atividade tende a permanecer na área, portanto em contato com os agentes agressores.

A norma força a permanência na atividade, o que vai ao longo do tempo acarretar, em muitos casos na morte ou deterioração da saúde do trabalhador, infringindo o mínimo existencial que é a manutenção de sua saúde para uma inatividade digna ou mesmo a sua morte antes de complementar as condições exigidas. Portanto, a alteração na forma como perpetrada fere também esse piso mínimo dos direitos fundamentais, caracterizando sua inconstitucionalidade. 
Por fim, não se olvida a possibilidade de uma Lei Complementar alterar a idade mínima estabelecida, porém frente a nossa realidade política, é questionável que haja uma redução para um patamar factível para a preservação da dignidade do trabalhador brasileiro.

\section{REFERÊNCIAS}

AGOSTINHO, T. V., Salvador, S. H., \& Silva, R. A nova aposentadoria especial e sua inviabilidade protetiva pela incompatibilidade do requisito etário a partir da PEC 06/2019 (Reforma da Previdência). REVISTA BRASILEIRA DE DIREITO SOCIAL, 2(2), 8-39. http://rbds.ieprev.com.br/rbds/article/view/107, Consultado em 08 mar. 2021.

ALEXY, Robert. Teoría de los Derechos Fundamentales. Ed. Centro de Estudios Políticos y Constitucionales. Madrid, 2002.

BARROSO, Luís Roberto. O direito constitucional e a efetividade de suas normas. $5^{\mathrm{a}}$ ed. Rio de Janeiro, Renovar, 2001.

BOBBIO, Norberto. A era dos direitos. 19ª Ed. Rio de Janeiro, Elsevier, 1992.

BONAVIDES. Paulo. Curso de Direito Constitucional. $13^{\text {a }}$ Ed. São Paulo. Malheiros Editores, 2003.

BRASIL. Constituição da República Federativa do Brasil de 1988. Brasília, DF:

Presidência da República, 2019. Disponível em:

http://www.planalto.gov.br/ccivil_03/constituicao/constituicaocompilado.htm. Acesso em: 10 mar. 2021

BRASIL. Emenda Constitucional 103. Brasília, DF: Presidência da República, 2019. Disponível em: http://www.planalto.gov.br/ccivil_03/constituicao/emendas/emc/emc103.htm. Acesso em: 10 mar. 2021

CANOTILHO, JJ Gomes. Direito Constitucional e Teoria da Constituição. Ed. Almedina,

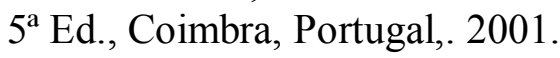

COSTA, Aline Moreira da. Direitos humanos e previdência social brasileira à luz do princípio da proibição do retrocesso social. Faculdade de Direito, USP, São Paulo, 2013. Doi:10.11606/D.2.2013tde-28072014. Acesso em: mar. 2021.

DWORKIN, Ronald. A Virtude soberana: a teoria e a prática da igualdade. $2^{\mathrm{a}} \mathrm{ed}$. Martins Fontes, São Paulo, 2011.

DWORKIN, Ronald. Levando os direitos a sério. $1^{\text {a }}$ Ed., Martins Fontes, São Paulo, 2002.

FERRAJOLI. Luigi. Por uma teoria dos direitos e dos bens fundamentais. Livraria do Advogado Editora. Porto Alegra, 2011. 
HOLMES. Stephen. SUSTEIN, Cass R. El costo de los derechos: por qué la libertad depende de los impuestos. Ed. Siglo Veintiuno, Buenos Aires, 2015.

HORTA. Raul Machado. Estudos de Direito Constitucional. Ed. Del Rey, $1^{\text {a }}$ Ed. Belo Horizonte, 1995.

LADENTHIN. Adriane Bramante de Castro. Reflexões sobre aposentadoria especial na EC 103/2019. Revista de direito do trabalho e seguridade social: vol. 46, n. 201, mar./abr. 2020.

LAZARI, Rafael José Nandim de. Reserva do possível e mínimo existencial - a pretensão da eficácia da norma constitucional em face da realidade. $2^{\mathrm{a}}$ ed, Curitiba, Editora Juruá, 2016.

MARTINEZ, Wladimir Novaes. Aposentadoria Especial em 420 perguntas e respostas. São Paulo, Ed. LTr, 2001.

MORAES, Alexandre de. Direito Constitucional. 32a . Ed. São Paulo: Atlas, 2016.

RIBEIRO. Maria Helena Carreira Alvim. Aposentadoria especial: regime geral da previdência social. Curitiba, Editora Juruá, 2004.

SARLET, Ingo Wolfgang. A eficácia dos direitos fundamentais. $8^{\mathrm{a}}$. Ed. Porto Alegre: Livraria do Advogado, 2007.

THEODORO, Marcelo Antônio. SILVA, Laís Batistuta. Custo do direito: Apontamentos sobre o conflito entre reserva do possível e mínimo existencial. Disponível no link: www.publicadireito.com.br. Acesso em 08 mar. 2021.

TORRES. Ricardo Lobo. O mínimo existencial e os direitos fundamentais. Revista de Direito Administrativo. Rio de Janeiro, 1989. in:www.bibliotecadigital.fgv.br. acesso em 08 mar. 2021.

VERISSIMO, Gesiele; MENDONCA, Raphael and MEYER, Armando. Mortalidade de mineiros brasileiros por câncer entre 1979-2005. Cad. saúde colet. [online]. 2013, vol.21, n.3, pp.281-288. ISSN 1414-462X. https://doi.org/10.1590/S1414-462X2013000300008, in: https://www.scielo.br/scielo.php?pid=S1414-

462X2013000300008\&script=sci_abstract\&tlng=pt, consultado em mar. 2021.

VIDAL. Marcílio Pompeu, G.; ARRAES de Alencar Pimenta, C. O Princípio da vedação do retrocesso social diante da crise econômica do século XXI. Revista Direito e Desenvolvimento, v. 6, n. 12, p. 216 - 237, Paraíba. 2017. 